\title{
CONSIDERAÇÕES ACERCA DO "IUDEX QUI LITEM SUAM FECIT"
}

\author{
Jaime Meira do Nascimento Júnior \\ Doutorando pela Faculdade de Direito da \\ Universidade de São Paulo
}

\begin{abstract}
Resumo:
O presente estudo tem por objetivo tecer uma breve reflexão acerca de um importante tema tratado pelo Direito Romano denominado Litem suam facere, o qual se mostra relevante, inclusive para os dias atuais, por versar acerca da responsabilidade civil do juiz por suas decisões nos casos apresentados pelos textos normativos. Nesse sentido, o trabalho ora apresentado, através de um estudo dos principais autores que trataram do tema, bem como da exegese de alguns fragmentos das fontes, procura estabelecer qual o efetivo alcance da expressão retromencionada bem como o seu tratamento jurídico.
\end{abstract}

\begin{abstract}
:
The present study intends to bring a reflection concerning a theme treated by the Roman Law called Litem suam facere, which has great importance including to the current days, because it concerns on the Judge's civil responsibility for his decisions in the cases related by the sources. So, the work for now presented, through a study of the main authors that have analysed the theme, as well as through the exegesis of some fragments of the sources, try to establish which is the reach of the mentioned expression as well as its juridical treatment.
\end{abstract}

Unitermos: Direito Romano; responsabilidade civil; quase-delitos; "Iudex qui litem suam fecit"

Sumário: I. Introdução; II. Litem suam facere: a. aspectos preliminares; b. conceito; III. Litem suam facere: a. responsabilidade civil; b. tutela jurídica cabível; c. sanção aplicável; IV. Conclusão; V. Bibliografia. 


\section{Introdução}

No âmbito da Ordo iudiciorum privatorum, o iudex sempre se apresentou como figura fundamental para a aplicação da justiça no caso concreto.'

Sua atuação ocorria na segunda fase do processo, denominada apud iudicem, que se iniciava após a litiscontestatio.

Desse modo, uma vez determinados os limites da demanda, o pretor redigia a fórmula, ${ }^{2}$ representando esta o parâmetro a ser observado por aquele que daria a sentença.

Nesta, ainda, seria determinada qual a condenação que deveria ser aplicada, bem como eventuais exceções que poderiam ser apresentadas pelo réu.

As partes, então, deveriam escolher, dentre os nomes constantes no album iudicum, quem seria o cidadão romano perante o qual as provas seriam produzidas $\mathrm{e}$ que teria por dever proferir uma decisão ao caso concreto.

Assim, o iudex era uma pessoa não ligada ao Poder Público e que, por sua conduta ilibada e condição social, recebia o munus publicum de julgar os litígios existentes.

I. Scgundo J. R. C. Tucci c L. C. Azcvedo, Lições de História do Processo Civil Romano, São Paulo, Revista dos Tribunais, pp. 41-5, numa fasc inicial a jurisdição cncontrava-sc ainda nas mãos dos pontificcs, os quais deram forma ao procedimento atravćs de simbolismos c rituais, num momento $\mathrm{cm}$ que dircito (iuls) c rcligião (fas) cram conccitos que não sc distinguiam. Alćm disso, haja vista a fragmentação das fontes no que toca ao periodo inicial da história de Roma, cmbora não se saiba por ccrto quais as limitações dos poderes do rci, tem-se que cstc cra o clicfe supremo, vitalício c único depositário da potestas publica, reunindo $\mathrm{cm}$ suas mãos, por força de scu imperium, dentre outros, o poder $\mathrm{de}$ julgar $\mathrm{cm}$ primeira $\mathrm{c} \mathrm{cm}$ última instância. Admitindo-sc que no processo arcaico, o processo descnrolava-sc integralmente perantc o rex, com o andar dos tempos c com o crescimento de Roma, os litigios foram sc tornando mais complexos, surgindo, disto, a necessidade de se criar magistraturas com especificas funçõcs jurisdicionais. Assim, scgundo a história tradicional (Dionísio de Halicarnasso, 4.25 ), tendo $\mathrm{cm}$ vista a progressiva laicização do dircito c o crescimento da atividade jurisdicional, o rei Sérvio Túlio (578-534 a.C.) desmembrou a justiça $\mathrm{cm}$ pública c privada. Assim, nos dois últimos séculos da realcza, os saccrdotes ccdem passo aos magistrados públicos, no que tange à distribuição da justiça sccular. Ainda, consoantc obscrvam os autores, o imperium ć transfcrido de forma mais limitada c cxclusiva a ccrtos magistrados, os quais passaram a deter o poder de declarar o dircito aplicável (iurisdictio). É provavelmente a partir desse momento que o procedimento passa a se desenrolar $\mathrm{cm}$ duas fases, uma diantc do pretor, in iure, c outra perante o iudex unus, apud iudicem, scrido cstc um cidadão romano que julgaria sobcranamentc $\mathrm{cm}$ nome do povo romano. Assim, cnquanto o pretor diria qual o dircito aplicávcl, o iudex, analisando as provas produzidas, scria o responsável pela sentença, decisão esta que deveria scr obedecida pela parte sucumbente.

2. A fórmula surgiu na segunda fase do processo romano, denominado periodo formulário. Trata-sc de um documento cscrito, no qual se fixam os pontos litigiosos da demanda, outorgando-sc ao iudex o poder de condenar ou absolvcr o réu, conforme fique ou não demonstrada a pretensão deduzida pela outra partc. A respeito, cf. J. C. Morcira Alves, Direito Romano, v. I, $10^{\text {al }}$ cd., Rio de Janciro, Forensc, 1995, p. 107 c J. R. C. Tucci c L. C. Azcvedo, Lições cit. (nota 1 supra), p. 89 c segg. 
Diante da importância deste personagem para a normalidade e para a correta distribuição da justiça, mostra-se importante o estudo de um dos principais quase-delitos, ${ }^{3}$ qual seja, o litem suam facere.

O objetivo do presente estudo é verificar a discussão tecida na doutrina sobre qual a hipótese em que se verificava tal instituto, bem como as consequiências dele decorrentes, de sorte a identificar o tratamento jurídico dado à matéria.

II. Litem suam facere: a: aspectos preliminares; b. conceito

II.a. Quanto mais se retorna no tempo, torna-se cada vez mais nítido o caráter privado do processo civil romano, podendo-se designá-lo quase como um procedimento arbitral.

Era, pois, o iudex privatus, pessoa comum escolhida dentre os cidadãos romanos em razão de suas condições pessoais de bonus vir.

Assim sendo, essa idoneidade pessoal era a base sobre a qual a segurança jurídica daquela época se sustentava, sendo, pois, o requisito necessário para a inscrição no chamado album iudicum.

Nesse passo, todo juiz procuraria julgar bem e de maneira honesta, sendo certo ainda que este juiz estaria compromissado mediante um juramento. Tratava-se, pois, do iudex iuratus. ${ }^{4}$

A decisão desse árbitro era, na verdade, um parecer, o qual era proferido após a instrução probatória.

Como este personagem não se encontrava ligado ao Poder Público, não havia uma hierarquização judicial, ou um sistema burocratizado que permitisse a revisão do julgamento.

3. Consoantc explica J. C. Morcira Alves, Direito Romano, v. II, 5" cd., Rio de Janciro, Forense, 1995, pp. $275 \mathrm{c}$ scgg., cmbora no dircito clássico o ius civile apenas reconhecesse como fonte de obrigaçào os quatro ilícitos classificados como delicta (furtum, rapina, dammum iniuria datum c iniuria), não podiam os romanos deixar de lcvar $\mathrm{cm}$ consideração outros atos ilícitos que acarretavam prcjuizos. Diantc disso, quando surgiu a classificação tripartida contida na obra Aureorum libri, atribuida a Gaio, quatro dessas situações foram classificadas dentre as variae causarum figurae, a saber, si iudex qui litem suam fecererit: effusum et deiectum: positum et suspensum; e receptum nautarum, cauponum, stabulariormm. Nas instituiçõcs de Justiniano (Inst. 4, 5), por outro lado, tais figuras foram inscridas, dentro de uma classificação quadripartita das fontes das obrigações nos chamados quasc-delitos.

4. Cf. I. Cremades c J. Paricio, La responsabilidad del juez en el Derecho Romano clasico in AHDE 54 (1984), p. 190. 
O dever primordial deste iudex era o de proferir a sentença, como atestam nitidamente as fontes ${ }^{\varsigma}$, sendo certo que, uma vez proferida, esta não poderia mais ser alterada, tendo em vista o princípio da intangibilidade das decisões.

Assim sendo, diante da Ordo iudiciorum privatorum, era a decisão deste juiz inatacável ${ }^{6}$ e, por conseguinte, executável, seja pela manus iniectio, no período mais antigo (legis actiones) ou pela actio iudicati, no âmbito do período formular. ${ }^{7}$

Somente mais tarde, com o crescimento do Império Romano, de pouco em pouco a atividade jurisdicional foi sendo transferida a magistrados oficiais, os quais, como verdadeiros funcionários públicos e com autoridade recebida por delegação do imperador, passaram a decidir as controvérsias.

Desse modo, na denominada fase da cognitio extraordinaria, havia uma estrutura judicial hierarquizada e burocratizada, a qual permitiu a revisão das decisões pela autoridade hierarquicamente superior.

A partir de então havia os juízes inferiores e superiores, o que implicou o surgimento de recursos (appellatio e supplicatio)

Mostra-se, portanto, evidente a magnitude e a importância de uma decisão correta proferida pelo iudex, para a solução da controvérsia.

De fato, o seu dever primordial era o de prolatar a sentença, dentro dos limites estabelecidos pelo pretor, fazendo-o com a idoneidade e licitude necessárias, em respeito ao juramento por ele prestado, de modo a não causar prejuízo às partes em razão da própria imutabilidade de seu parecer.

II.b. Diante desse quadro, a grande questão relativa ao tema sub examen, refere-se exatamente ao seu conceito. Quando o iudex litem suam faciebat?

Inicialmente, cumpre ressaltar não se enquadrar em tema de litem suam facere a hipótese do iudex venal ou corrupto.

5. Nesse scntido, Iul. 5 dig., D. 5, 1, 74 pr: "De qua re cognoverit iudex, pronuntiare quoque cogendus erit." A respeito, cf. ainda I. Crcmades c J. Paricio, La responsabilidad cit. (nota 4 supra), p. 190.

6. Esta assertiva deve ser tomada como a regra geral. Por óbvio havia possibilidades de sc infirmar a decisão do inclex. Todavia, não sc tratavam de rccursos propriamcntc ditos. Assim, v.g., podc-sc citar os casos da in integrum restitutio $\mathrm{c}$ da infitiatio.

7. Nesse sentido, cf. J. R. C. Tucci c L. C. Azcvedo, Liçōes cit. (nota 1 supra), pp. 68 c 131. 
Esta era tutelada pelo ius publicum, cuja sanção prevista na Lei das XII Tábuas $(9,3)$ era a pena capital. ${ }^{8}$

Por outro lado, tampouco se inclui na espécie a situação em que o juiz profere uma sentença injusta.' Em tese, a principal solução cabivel neste caso seria a restitutio in integrum, ${ }^{10}$ quando fosse cabível.

As fontes, ao tratarem do tema, preceituam hipóteses específicas no que tange ao tema em estudo.

Nesse sentido, assevera Gaio:"

Gai. 4, 52: "Debet autem iudex attendere, ut, cum certae pecuniae condemnatio posita sit, neque maiores neque minoris summa posita condemnet, alioquin litem suam facit. Item si taxatio posita sit, ne pluris condemnet quam taxatum sit; alias enim similiter litem suam facit. Minoris autem damnare ei permissum est. At si etiam ......... qui formulam accipit, intendere debet, nec amplius.... certa condemnatione constringi ...... velit."
Gai. 4, 52: "Sendo a condenação pedida em quantia certa, o juiz não deve condenar o réu em importância maior nem menor; da reclamada pelo autor; do contrário, faz sua a lide. E se também ... que recebe a fórmula, deve pedir não mais... ser obrigado por uma condenação certa, ... até onde quiser."

8. Scgundo obscrva A. D'Ors, Litem stiam facere in SDHI 48 (1982), p. 369, isto sc bascia numa conhecida passagem da clisputatio entre o jurista Africano c o filósofo Favorino, onde jurista defende a idćia durcza da lei decenviral, citando a cstc propósito a pena capital imposta ao juiz vcnal A respeito, v. Gell. , N. A., 10, 1, 7 c 20, 1, 7-8. Contudo, alcrta o autor que referido testemunho deve ser encarado com cautcla, pois provavelmente o preceito decenviral, se realmente existiu, referia-sc a um juiz que condenou, por dinhciro, um réu criminal. Aduz ainda que no dircito clássico, o juiz corrupto responderia por crimen falsi, previsto da Lex Cornelia, a qual não impunha a pena capital.

9. Reitcre-sc que não existia, no período clássico, um proccdimento cspecífico enderç̧ado a corrigir a decisão injusta.

10. A respcito das formas de sc infirmar a decisão do iuclex, v. nota 6 supra. Por outro lado, scgundo

G. Cervenca, Restitutio in integrtım in NNDI, t. XV, $3^{\text {a }} \mathrm{cd}$., Turim, Unionc Tipografico, 1957, pp. 740-4, tratava-se referido instituto de um remédio concedido pclo Magistrado, com basc $\mathrm{cm}$ scu poder dc imperium, visando a rescindir os cfcitos de um ato jurídico qualquer, scja cle um negócio, ou um processo, o qual, cmbora sendo formalmentc válido, foi concluído com um concurso de circunstâncias que tornaram scus cfcitos contrários aos princípios da aequitas. V. Arangio-Ruiz, Istituzioni di Diritto Romano, 14: cd., Nápoles, Jovenc, 1984, p. 106, a scu turno, entende tratar-sc de um provimento o qual torna nulo um ato jurídico qualquer, scja de dircito matcrial, scja processual. A restitutio in integrum advém de uma caussa cognita, com basc $\mathrm{cm}$ uma valoração da rclevância das circunstâncias invocadas $\mathrm{c} \mathrm{cm}$ hipótcscs que são geralmentc contempladas no Edito. Assim, diantc do pedido da parte c depois do cxame das circunstâncias retro aduzidas, recusam-sc os remćdios judiciais que pelo dircito cstrito se csperaria ou se concederia, a fím de climinar os cfeitos do ncgócio civado de violência.

I1. A. Corrcia c G. Sciascia, Manual de Direito Romano, v. II, $2^{`}$ cd., São Paulo, Saraiva, 1955, pp. 242-3. 
Em outro texto contido no Digesto atribuído a Ulpiano, ${ }^{12}$ apresenta-se un conceito diverso:

$$
\text { Ulp. } 26 \text { ad ed:, D. 5, 1, 15, 1: }
$$

Iudex tunc litem suam facere intellegitur, cum dolo malo in fraudem legis sententiam dixerit (dolo malo autem videtur hoc facere, si evidens arguatur eius vel gratia vel inimicitia vel etiam sordes), ut veram aestimationem litis praestare cogatur.
Ulp. 26 ad ed., D. 5, 1, 15, 1: "Entende-se então que o juiz faz a lide sua, quando diz a sentença com dolo mal em fraude à lei (mas parece fazer isto com dolo mal, se evidentemente acusa por favor, inimizade ou ainda por mesquinharia), de modo que será compelido a prestar uma verdadeira estimação da lide."

Segundo a opinião de A. D'Ors, ${ }^{13}$ em sentido técnico, litem suam facere deve ser entendido como o fato de um juiz se sub-rogar na posição do demandado, quando deixa de cumprir o seu dever de dar a sentença no momento em que havia de fazê-lo, quando prolata uma decisão nula, ou fora dos limites da fórmula.

No que toca ao outro conceito, o autor retromencionado, ${ }^{14}$ após minuciosa análise da Lex municipii Flavi Irnitani e de um fragmento do livro 12 ad edictum do mesmo Ulpiano (P. Ant. I, 22), conclui que o referido fragmento do Digesto apresentase contraditório em relação a estes textos, tratando-se, portanto, de adulteração, ${ }^{15}$ na medida em que entende que o jurista romano retro aduzido entenderia por litem suam facere a conduta indicada por Gaio. ${ }^{16}$

Aduz támbém existirem problemas no bojo do texto do Digesto, na medida em que, v.g., a expressão lex contida no fragmento parece não se referir a uma lei ou plebiscito, mas à ordem jurídica como um todo, emprego este que, no período clássico, não mostra próprio aos juristas.

12. Litem cit. (nota 8 supra), pp. $373 \mathrm{c} \mathrm{segg.}$

13. A. D'Ors cntende que o iudex que profere sentença além dos limites da fórmula não prolata decisão alguma, devendo csta scr cquiparada a uma scntença nula.

14. D’Ors, Litcm cit. (nota 8 supra), p. 373.

15. Intcressante notar que A. D'Ors chega a afirmar que os compiladores tomaram cstc texto de uma cdição adultcrada dos comentários ao cdictum, de Ulpiano. Ncsse sentido, cf. Litem cit. (nota 8 supra), p. 378.

16. O mesmo autor observa inclusive cxistir um crro na inscriptio do fragmento, pois, na verdade, o correto scria o liviro 23 ad. cd., não o 21 que versa accrca dos adpromissorcs. Nesse scntido, cf. Litem cit. (nota 8 supra), p. 377. 
Por outro lado, a expressão in fraudem legis seria ambígua, na medida em que não resulta congruente com a exigência do dolus malus calcado nas motivações subjetivas indicadas (vel gratia, vel inimicitia, vel etiam sordes), as quais parecem refletir melhor uma injustiça de fundo do que uma inobservância sub-reptícia de imperativos legais.

Desta maneira, na opinião de A. D'Ors, litem suam facere estaria relacionado ao descumprimento do dever primordial do iudex, que é o de dar uma sentença válida.

Ressalte-se ainda que se o juiz fugir aos limites da fórmula, faz a lide sua, na medida em que, segundo o autor retromencionado, haveria decisão nula, o que equivale à ausência de sentença. ${ }^{17}$

Quanto a este aspecto, interessante é a reflexão trazida por I. Cremades e J. Paricio. ${ }^{18}$

Segundo explicam, alguma confusão poderia surgir da análise do seguinte fragmento, onde se indica que tenha um juiz condenado a mais ou ao menos não poderá alterar sua sentença, pois "male seu bene officio functus est": 19

Ulp. 51 ad. Sab., D. 42, 1, 55: Iudex posteaquam semel sententiam dixit, postea iudex esse desinit: et hoc iure utimur, ut iudex, qui semel vel pluris vel minoris condemnavit, amplius corrigere sententiam suam non possit: semel enim male seu bene officio functus est.
Ulp. 5 I ad. Sab., D. 42, 1, 55: “O juiz, após proferir uma vez a sentença, deixa depois de ser o juiz. A lei que se observa é que uma vez tenha condenado a mais ou a menos, não possa corrigir a sua sentença; porque bem ou mal exerceu uma vez o seu oficio."

De fato, em momento algum se afirma nesse texto a validade da decisão que contraria o teor da fórmula. Tão-somente assinala que a sentença fora dos limites da orientação pretoriana seria eficaz e que o juiz, bem ou mal, havia cumprido o seu dever.

17. Lirem cit. (nota 8 supra), p. 372. No mesmo sentido, I. Cremades c J. Paricio, La responsabilidad cit. (nota 4 supra), p. 183.

18. La responsabilidad cit. (nota 4 supra), pp. 183-4.

19. Tradução bascada cm G. Vignali, Corpo del Diritto, Nápoles, Viccnzo Pczzuti, 1856, T. VI, p. $1.151 \mathrm{c} \mathrm{cm} \mathrm{A.} \mathrm{Watson,} \mathrm{The} \mathrm{Digest} \mathrm{of} \mathrm{Justinian,} \mathrm{v.} \mathrm{Il,} \mathrm{Philadelphia,} \mathrm{Pennsylvania,} 1998$. 
Não serve para afirmar a validade do julgamento que foge dos limites da fórmula.

Por outro lado, haveria uma exceção à regra. Se o juiz não ajustasse sua decisão à fórmula porque os litigantes acordaram, depois da litiscontestatio, em não respeitá-la, referida decisão seria dotada de validade, de sorte que, em conseqüência, não se poderia falar em responsabilidade do iudex por litem suam facere.

Nesse sentido: ${ }^{20}$

Iul. 5 dig., D. 5, 1, 74, 1: Iudex, qui usque ad certam summam iudicare iussus est, etiam de re maiori iudicare potest, si inter litigatores conveniat.
Iul. 5 dig., D. 5, 1, 74, 1: “O juiz, o qual foi ordenado julgar até uma certa quantia, pode pois julgar por coisa maior, se os litigantes acordarem."

Outro ponto que merece destaque é a origem da expressão que denomina $o$ instituto que se estuda no presente trabalho.

Em época mais antiga, a expressão faria referência à apropriação da coisa objeto do litígio. Era o caso, do juiz que, indevidamente, retinha o bem disputado pelas partes e ao qual lhe fora conferida a guarda (iudex sequester). Agia então como verdadeiro depositário infiel, sendo equiparado a um ladrão.

Nesse passo, embora as fontes não atestem esta hipótese, com a evolução do direito, a expressão litem suam facere teria adquirido um sentido figurado. Assim, o iudex que não profere a sentença torna seu o litígio, como se tivesse apropriado da coisa litigiosa. $^{21}$

Finalmente, interessante notar que, segundo A. D'Ors, o conceito de litem suam facere sofreu alterações no período pós-clássico, exatamente pelo surgimento dos recursos contra a sentença.

Se antes a ação pretoriana fora criada para responsabilizar o iudex por ter proferido decisão nula ou ter deixado de prolatá-la no tempo devido, nesta fase mais tardia a ação pretoriana passou a corrigir as injustiças dos juízes, não sendo mais necessária uma ação privada para o juiz que não deu sentença, razão pela qual defende que o fragmento atribuído a Ulpiano trata-se de verdadeiro texto inserido pelos compiladores e não de simples interpolação.

20. Bascado cm G. Vignali, Corpo cit. (nota 19 supra), T. II, p. $871 \mathrm{c} \mathrm{cm} \mathrm{A.} \mathrm{Watson,} \mathrm{The} \mathrm{Digest} \mathrm{of}$ Justinian, v. I, Philadelphia, Pennsylvania, 1998.

21. I. Cremades c J. Paricio, La responsabilidad cit. (nota 4 supra), pp. 185-6. 
De qualquer maneira, embora muito haja o que se discutir a respeito do exato sentido do tema ora estudado, sobretudo no que toca às eventuais incorreções dos textos das fontes, afigura-se razoável considerar o instituto em ambos os significados trazidos.

Mesmo porque atualmente os estudiosos do Direito Romano, embora não desprezem por completo a existência de interpolações, tendem a considerar válidos, fidedignos e clássicos os textos trazidos até a presente época. ${ }^{22}$

Nesse sentido, pode-se citar a opinião de F. Lamberti, ${ }^{23}$ que refuta a tese de A. D'Ors, defendendo a idéia de que o fragmento de Ulpiano somente teria sido modificado na explicação acerca do dolus malus inserida entre parênteses.

A autora, dessa maneira, discorda que tenha sido o texto totalmente modificado pelos compiladores, aduzindo que, em verdade, a hipótese ali delineada, mais do que definir o que seria litem suam facere, visava a explicar o fragmento anterior (Ulp. 21 ad ed., D. 5, 1, 15 , pr.), onde Ulpiano trata do caso do iudex filiusfamilias qui litem suam fecit. ${ }^{24}$

Ademais, observa que o fragmento de Gaio em momento algum especifica o elemento subjetivo necessário à configuração da hipótese.

Assim, melhor tomar-se um conceito de litem suam facere mais genérico, envolvendo as duas hipóteses, de sorte a permitir uma visão ampla do problema. ${ }^{25}$

22. A respeito do problema das interpolaçõcs das fontes, cf. G. Puglicsc, Istituzioni di Diritto Romano, 2: cd., Torino, Giappichelli, 1990, pp. 182-4, scgundo o qual, a partir de 」930, a pesquisa de interpolações c de outras alterações continuou a ocorrer, mas de forma cada vez menos significativa, a ponto de que, hojc, analisam-sc os textos da compilação justinianćia, bem como aquclas fontes pós-clássicas anteriorcs a Justiniano, com razoávcl confiança $\mathrm{cm}$ sua capacidade de reconstruir o dircito do período clássico. Outrossim, sobrc o conccito de intcrpolação, v. A. Guarino, Diritto Privato Romano, 8" cd., Napoli, Jovene Napoli, 1988, pp. 126-8.

23. Riflessioni in tema di litem suam facere in Labeo 36 (1990) 2, p. 249.

24. Ncsse scntido, op.cit., nota 21 , p. 250. E ainda: Ulp. 26 ad cd., D. 5, 1, 15 pr.: "Filius familias iudex si litem suam faciat, in tantam quantitatem tenetur; quae tunc in peculio fuit, cum sententiam dicebat. (Sc um filho de familia juiz fizcr a lide sua, scrá obrigado $\mathrm{cm}$ tanta quantidade que cntão tiver $\mathrm{cm}$ pecúlio, no momento que tiver dado a sentença.)

25. Obscrve-sc que muitos autores na doutrina, ao tratarem do tema, adotam como conceito de litem suam faccre a hipótesc prevista no fragmento de Ulpiano criticado por A. D'Ors e I. Cremades $\mathrm{c} J$. Paricio. Assin, v.g., A. Guarino, Diritto cit. (nota 22 supra), p. 884, a definc como a ação dada contra o juiz que, dolo malo in fraudem legis, emitisse uma sentença injusta. No outro sentido, P. F. Girard, Manuel Elémentaire de Droit Romain, 4" cd., Paris, Arthur Rousscau, 1906, p. 635, scgundo o qual, o juiz faz o processo scu não apcnas quando prolata uma sentença ruim ou por ncgligência, mas tambćm por ter faltado com o scu dever de uma mancira qualquer, como, v.g., deixou de aprescntá-la no dia combinado para prolatar a sentença. Adotando ambos os sentidos, G. Puglicsc, Istituzioni cit. (nota 22 supra), p. 609, que cntende tratar-sc da hipótcse $\mathrm{cm}$ que o juiz condenou a soma diversa da cstabclecida pela fórmula, tenha julgado injustamente por inimizade, favor ou corrupçào $c$ tenha sido omisso a julgar no tcrmo prcscrito, causando a cxtinção do proccsso. 
Trata-se portanto de um quase-delito, dentro da classificação quadripartita de Justiniano, no qual o iudex deixa de prolatar a decisão no tempo devido ou a profere fora dos limites estabelecidos pela fórmula.

III. Litem suam facere: a. responsabilidade civil; b. tutela juridica cabivel; c. sanção aplicável.

III.a. Ao tratar da natureza da responsabilidade civil no caso de liten suam facere, a doutrina não se mostra pacifica, vislumbrando-se a existência de três correntes que trataram do tema.

Nesse sentido, conforme explica F. Lamberti, ${ }^{26}$ a teoria que sustenta ser baseado o instituto sub examen em uma conduta dolosa do iudex aduz que, caso houvesse responsabilidade por imprudentia no período das legis actiones ou no formulário, a função judicial seria exercida com grande relutância, tendo sido altamente impopular. Desse modo, as hipóteses previstas nas Institutas de Gaio e no Papiro de Antinópolis (P. Ant. I, 22) demandariam, pelo menos a presença de um dolo presumido.

Um segundo setor da doutrina, orientou-se no sentido da responsabilidade culposa do iudex no final do período clássico. A actio contra iudicem qui litem suam fecit inicialmente teria sido utilizada para punir somente a hipótese de negligência processual, e apenas no final do período clássico, teria sido estendida para casos em que houvesse um comportamento fraudulento do iudex.

Verifica-se também um terceiro ramo da doutrina, a qual defende a responsabilidade objetiva do iudex, sendo esta, segundo F. Lamberti, ${ }^{27}$ aceita por um maior número de autores. Tal explicação facilitaria a solução da controvérsia entre as definições de Gaio e de Ulpiano, ${ }^{28}$ as quais seriam enumerações casuísticas das hipóteses de litem suam facere.

Esta última posição, ademais, mostra-se coerente se for levado em conta que o instituto analisado é classificado, no capítulo concernente às fontes de obrigação, como um quase-delito, o qual dispensa a existência de dolo para o surgimento da responsabilidade civil. ${ }^{29}$

26. Riflessioni cit. (nota 23 supra), pp. 245-8

27. Riflessioni cit. (nota 23 supra), p. 247.

28. V. item II.b. supra.

29. Ao tratar das fontes de obrigação no Dircito Romano, J. C. Morcira Alves, Direito cit. (nota 3 
Nesse sentido: ${ }^{30}$

Inst. 4, 5 pr: Si iudex litem suam

fecerit, non proprie ex maleficio obligatus videtur. Sed quia neque ex contractu obligatus est et utique peccasse aliquid intellegitur, licet per imprudentiam: ideo videtur quasi ex maleficio teneri ${ }^{<}$et in quantum de ea re aequum religioni iudicantis videbitur, poenam sustinebit
Inst. 4, 5 pr.: "O juiz que fizer sua a demanda não se obriga propriamente por um delito; mas como também não está obrigado por um contrato, mas por certo se entende que prevaricou, embora por imprudência, é por isso considerado como responsável por um quase-delito: e sofrerá a pena que parecer eqüitativa à consciência do juiz."

III.b. No que tange à ação cabível, a doutrina apresenta uma evolução de acordo com o período em que ocorresse o litem suam facere.

supra), pp. 32-6, explica que Gaio, cm suas Institutas vislumbrou uma classificação bipartida. Ncssc passo, toda obrigação nasccria dc um contrato ou dc um delito. Em scguida, $\mathrm{cm}$ suas anreorum Libri (Gai. 2 aur. D. 44, 7, 1 pr.), ampliou a classificação, inscrindo uma terccira catcgoria denominada de várias figuras de causas (ex variis calısartum figuris). Os contratos scriam obrigaçõcs nascidas rc, vcrbis, litteris c consensus. Os delitos seriam os quatro seguintes: firtum, rapina, damnum iniuria datum e iniuria. E na terccira classificação scriam inscridas aquelas que não decorreriam de acordo de vontades, tais como as quc advêm da tutcla $\mathrm{c}$ as do herdciro com rclação ao legatário. O próprio Gaio parecc percebcr a imperfeição de sua classificação, pois, referindo-sc à repetição do pagamento indevido, ressalta que aquele que dá a coisa com a intenção de pagar, busca, na verdade, cxtinguir c não contrair um ncgócio (Gai. 3, 91). Observe-sc ainda que Gaio apenas classifica como obligationes aquelas reconhecidas pclo ius civilc $\mathrm{c}$ não as do ius honorarium, às quais os juristas clássicos denominavam de actiones tencri ou debita. Já nos aureorum Libri somente as obrigações decorrentes da vontade são classificadas como contratos. No que tange aos delitos, persistem os mesmos que são mencionados nas Institutas. Finalmente, nas várias figuras de causas são introduzidos os atos licitos quc não são bilatcrais $\mathrm{c}$ quc geram obligationes (v.g., gestão de negócios, tutcla), bem como ilícitos que o ius civile não enquadra na categoria de delicta, mas contra os quais o pretor concedida ação. Nas Institutus de Justiniano, diversamente, não sc verifica a diferenciação entre obligationes c actiones tencri ou debita, tendo clas se fundido nas denominação genérica obligationcs. Diante disso, nos contratos, inscriam-sc os acordos de vontade que geram obrigaçõcs; nos delitos as quatro figuras anteriormente mencionadas; nos quasc-contratos os atos lícitos unilatcrais dos quais resultam obrigações c, finalmentc, nos quasc-dclitos, os ilícitos aos quais o pretor concedia ação na ausĉncia de remédio específico no ius civile. Ainda scgundo J. C. Morcira Alves, Direito cit. (nota 3 supra), pp. 34-5, cxistc divergência doutrinária no que tange à interpretação destas três classificações, cmbora não haja dúvidas no sentido de que clas resultaram de um processo de cvolução. Dc acordo com a opinião dominantc, sendo a classificação bipartida de Gaio incompleta, refcrido jurista numa obra destinada à prática (os Rerum Cottidianarum Libri ou Aureorum) tentou corrigir a deficiência, introduzindo a terccira catcgoria. Justiniano mais tardc, visando a apcrfeiçoar a classificaçăo, introduziu a quadripartição, inserindo as figuras dos quase-contratos c quasc-delitos (estcs últimos como sendo os ilicitos sancionados pclo prctor).

30. Trad. por A. Corrcia c G. Sciascia, Manual cit. (nota 11 supra), pp. 584-5. 
Em época primitiva, consoante explicam I. Cremades e J. Paricio, ${ }^{31}$ o testemunho mais antigo que se dispõe é o episódio narrado por Macróbio

(Saturnalia 3, 16, 15 [2.12]) acerca dos juizes bêbados que, quase não se mantendo em pé, vão sentenciar.

Segundo aduzem, tal episódio teria ocorrido por volta do ano 161 a.C., ou seja, em época anterior à Lex Aebutia, ainda no período da legis actiones.

A doutrina, ao tratar do tema, aponta para esse período, três hipóteses prováveis de sanção:

a) ocorreria uma translatio iudicii, de sorte que a demanda continuaria correndo só que agora contra o juiz;

Segundo, A. D'Ors, ${ }^{32}$ M. Voigt teve uma intuição acertada ao pensar em uma espécie de translatio iudicii, pela qual o iudex qui litem suam fecit era colocado na mesma posição do demandado, contra o qual o juízo havia caducado. De qualquer modo, entende haver sempre a dúvida de como a ação frustrada pela omissão do juiz podia dirigir-se contra ele em lugar do anterior demandado, pois não se conhece o regime da translatio iudicii na época das legis actiones.

b) o iudex seria multado (multae dictio) ou estaria o demandante frustrado autorizado a tomar algo do juiz que descumpriu o seu dever (pignoris capio);

I. Cremades e J. Paricio ${ }^{33}$ entendem ser pouco provável que fosse o iudex multado, tendo em vista o limitado papel que o órgão jurisdicional desempenha em época antiga.

Quanto ao segundo, também seguem o mesmo raciocínio, apesar do incompleto testemunho de Gaio sobre a legis actio per pignoris capionem. A suposição de uma sanção semelhante contra os juízes deve-se a que em relação ao arbiter ex compromisso, parece seguir-se em época clássica, um regime parecido, e nos árbitros compromissários talvez poderia sobrevir de alguma maneira o mesmo sistema dos juizes primitivos.

c) caberia contra o iudex qui litem suam fecit a manus iniectio. ${ }^{34}$ Mas isso, segundo alerta D'Ors, ${ }^{35}$ pressuporia uma manus iniectio pro

31. La responsabilidad cit. (nota 4 supra), p. 187.

32. Litem cit. (nota 8 supra), pp. 380-1,

33. La responsabilidad cit. (nota 4 supra), pp. 187-8.

34. I. Cremades c J. Paricio, La reponsabilidad cit. (nota 4 supra), p. 188, sustentam ser csta a hipótese mais provávcl, citando como reforço de argumentação as Institutas de Gaio (Gai. 4, 26-29). Como muitas leis deram a manus inicctio $\mathrm{em}$ muitos casos, scria factível supor que alguma lci a tcria concedido contra o iudex qui litem suam fecit.

35. Litem cit. (nota 8 supra), p. 380. 
iudicato, já que precisamente se dava quando, por omissão do juiz que deveria ter sentenciado, não havia uma condenação judicial e tampouco esta conjectura nos aclara o ulterior regime clássico, no qual não se trata de uma actio iudicati, senão uma ação pretoriana especialmente criada para o suposto de omissão de sentença.

De qualquer maneira, conforme acentua o autor retro aduzido e também P. F. Girard ${ }^{36}$ existe grande dificuldade para se determinar como era reprimida a atitude do iudex antes do advento da tutela pretoriana. De fato, quanto mais se retorna à fase primitiva, mais escassas são as fontes jurídicas que permitiriam o conhecimento exato do tratamento dado ao instituto.

Já no período clássico, o pretor concedeu uma actio in factum ${ }^{37}$ in bonum et aequum concepta ${ }^{38}$ para o caso vertente, a qual permitiria a graduação da pena de acordo com as circunstâncias. ${ }^{39}$

Ademais, consoante observava Gaio: ${ }^{40}$

Gai. 3 rer. cott., D. 50, 13, 6: "Si iudex litem

Gai. 3 rer. cott., D. 50, 13, 6:: "Se

36. Manuel cit. (nota 23 supra), p. 635, n. 4.

37. Nessc sentido, E. Valiño, Las relaciones básicas de las acciones adyecticias in AHDE 38. (1968), p. 463. Por outro lado, ao tratar da classificação das açõcs no dircito romano, P. Bonfantc, Istituzioni di Diritlo Romano, $9^{\mathrm{i}} \mathrm{cd}$., Milão, Dott. Francesco Vallardi, 1932, pp. 112-3, explica que as actioncs in factum cram aquelas que sc basciam não $\mathrm{cm}$ relaçõcs conhccidas $\mathrm{c}$ qualificadas, mas $\mathrm{cm}$ fato novo, que não possui uma configuração $\mathrm{c}$ denominação própria $\mathrm{c}$ tampouco ć reconliccida ou resumida $\mathrm{cm}$ algum modo no ius civilc. Por isso, costumam scr designadas pclo fato que lhes dcu origcm. Alćm disso a cxpressão in factum também cra cmpregada cm um outro sentido, mais cstrito, significando as ações que o Prctor concedia a cada vez para circunstâncias cspcciais em contradição com as ações civis c pretorianas garantidas pclo Edito Pcrpétuo. A. Burdesc, Manuale di Diritto Romano, Turim, Unione Tipografico, 1964, p. 115, obscrva que se tratava do campo de atuação precípuo da atividade pretoriana. Nestas a intentio relativa à fórmula (in factum conceptae) prescindindo de qualquer rclação com a fórmula de ações civis, contém a direta descrição das circunstâncias de fato, cuja cxistência ć pressuposto para a condemnatio.

38. As açõcs in bonum et aequum concepta são aquelas nas quais tem o juiz a faculdade de valorar a condenação na quantia que pareccr justa. Rcfercm-sc a uma categoria de ações obrigacionais $\mathrm{cm}$ que, não cxistindo uma relação rigorosamente determinada pela lei ou pela fórmula do pretor, o iudex podia $\mathrm{c}$ devia buscar ex bona fide o quanto fosse devido às partes. A cstas sc opunham as actiones stricti iudicia. A distinção repousa na maior ou menor margem de arbitrio permitido ao julgador. Observe-se ainda que nos iudicia bonae fidei mesmo quc a partc não opusessc a exceptio doli, o iudex poderia considcrá-lo na fasc apud iudicem muito cmbora não estivesse inscrida na fórmula. Nesse sentido, cf. P. Bonfante, Istitutitioni cit. (nota 37 supra), pp. 109-11

39. Nessc scntido, cf. E. Cuq, Manuel des Institutions Juridiques des Romains, Paris, Plon-Nourrit, 1917, pp. 589-90.

40. Vidc ainda Inst. 4, 5 pr c Gai. 3 aur., D. 44, 7, 5, 4. 
suam fecerit, non proprie ex maleficio obligatus videtur: sed quia neque ex contractu obligatus est et utique peccasse aliquid intellegitur, licet per imprudentiam, ideo videtur quasi ex maleficio teneri in factum actione et in quantum de ea re aequum religioni iudicantis visum fuerit, poenam sustinebit." o juiz fizer a lide sua, não parece obrigado propriamente por delito, mas porque não foi obrigado por contrato $e$ se compreende que cometeu delito, ainda que por imprudência, por isso parece ser obrigado quase por delito com a ação in factum e sofrerá a pena em quanto parecer justo, para esta coisa, à consciência do juiz."

\section{III.c. A sanção cominada seria in id quod aequum iudici videbitur. ${ }^{41}$}

Desse modo, o pretor estaria livre para, de acordo com as contingências de cada caso concreto, aplicar a pena pecuniária cabível, sendo certo que, nos casos mais graves, em que houvesse dolo malo in fraudem legis, a condenação poderia atingir o valor da lide (vera aestimatio litis), sem prejuízo ainda da sanção criminal cabivel. ${ }^{42}$

\section{Conclusão}

Em que pesem as discussões doutrinárias no que toca ao tema em estudo, as quais aliás não são poucas, consoante observa E. Cuq, ${ }^{43}$ desde a Lei das XII Tábuas, o juiz que não cumprisse com o seu dever fazia o processo seu.

Assim, v.g., se não se apresentava no fórum no dia e hora fixados pelo pretor sem se justificar ou obter um prazo (vacatio) ou se ele não prolatasse a sua decisão nos limites fixados pela fórmula.

Nesses casos, o juiz fazia a lide sua e, portanto, deveria suportar os riscos do processo, podendo ser condenado a ressarcir o demandante até o valor da lide.

Tendo em vista a rigidez da Lei das XII Tábuas, o Pretor concedeu uma actio in factum a qual permitiu graduar a pena em razão das circunstâncias dos casos.

41. Nessc sentido, A. Guarino, Diritto cit. (nota 22 supra), pp. 884.

42. Cf. E. Cuq, Manuel cit. (nota 39 supra).

43. Id.Ibid. (nota 42 supra).'. 
Esta ação pretoriana era intransmissível ${ }^{44}$ aos herdeiros do iudex e, caso este fosse filiusfamilias somente estaria obrigado até o valor de seu pecúlio, quantia esta calculada com base no dia em que praticou o quase-delito.

Desse modo, seria colocado na posição em que se encontrava o demandado, respondendo até o limite do valor da pleiteado pelo autor da ação.

São Paulo, julho de 2001.

44. Quanto a cstc aspecto, afigura-se de rigor mencionar a divergência entre Ulpiano c Juliano. Este defendia que a ação sub examen cra, ao revćs, transmissivel aos herdciros. Ncssc sentido: Ulp. 5 ad cd., D. 5, 1, 16: Iulianus autem in heredem iudicis, qui litem stam fecit, putat actionem competere: quae sententia vera non est et a multis notata est. (Juliano, por outro lado, supõc compctir ação contra o herdciro do juiz que fez a lide sua: cuja sentença não ć verdadcira c foi reprovada por muitos). A doutrina diverge accrca do porquê das interpretações diversas aprescntadas pelos juristas. Assim, v.g., A. D'Ors, após realizar um estudo paralclo da hipótese do Magistrado que se descuida do dever de cxigir cauçào do tutor, hipótese cm que também existe divergência cntre os juristas romanos retromencionados, (Litcm cit. (nota 8 supra), p. 384-7), conclui que a posição de Juliano representaria opinião proferida antes da publicação Edito que conferiu a ação in factum para o caso. I. Cremades $\mathrm{c}$ J. Paricio (La responsabiliedad cit. (nota 4 supra), p. 195), a scu turno, após analisarcm as situaçõcs retro aduzidas, cntendem que, cmbora scja a divergência decorrente de fatorcs temporais, a opinião de Juliano, a scu ver, cstaria calcada nas contingências do Ordo privatorum iudiciorum, o qual não permitia a interposição de recurso para a corrç̧ão da decisão nula. Assim, a opinião de Ulpiano, o qual pugna pela intransmissibilidade da ação sub cxamen, cstaria rclacionada à cxistência, já numa fase postcrior (cxtraordinaria cognitio), de meios aptos a cnscjarcm a reforma da decisão gucrrcada (appellatio c suplicatio). Dessc modo, atć Juliano, a ação scria passivamente transmissivel. 
V. Bibliografia

ARANGIO-RUIZ, Vicenzo, Istituzioni di Diritto Romano, 14“ ed., Napoli, Jovene, 1984.

AZEVEDO, Luiz Carlos de, e TUCCI, José Rogério Cruz e, Lições de História do Processo Civil Romano, São Paulo, Revista dos Tribunais, 1996.

BONFANTE, Pietro, Istituzioni di Diritto. Romano, $9^{\text {a }}$ ed., Milano, Francesco Vallardi, 1932.

BURDESE, Alberto, Manuale di Diritto Romano, Torino, Unione Tipografico, 1964.

CERVENCA, Giuliano, Restitutio in integrum in NNDI - Novissimo Digesto Italiano, 3" ed., Torino, Unione Tipografico, 1957, tomo XV, pp. 740-4.

CORREIA, Alexandre, e SCIASCIA, Gaetano, Manual de Direito Romano, v. II, $2^{\text {a }}$ ed., São Paulo, Saraiva, 1955.

CREMADES, Ignacio, e PARICIO, Javier, La responsabilidad del juez en el Derecho Romano clasico in AHDE - Anuario de Historia del Derecho Español 54 (1984), pp. 179-208.

CUQ, Edouard, Manuel des Institutions Juridiques des Romains, Paris, PlonNourrit, 1917.

D'ORS, Alvaro, Litem suam facere in SDHI - Studia et Documenta Historiae et Iuris 48 (1982), pp. 368-94.

GIRARD, Paul Frédéric, Manuel Elémentaire de Droit Romain, 4" ed., Paris, Arthur Rousseau, 1906.

GUARINO, Antonio, Diritto Privato Romano, $8^{\mathrm{a}}$ ed., Napoli, Jovene Napoli, 1988.

LAMBERTI, Francesca, Riflessioni in tema di litem suam facere in Labeo Rassegna di Diritto Romano 36 (1990) 2, pp. 218-66.

MOREIRA ALVES, José Carlos, Direito Romano, v. I, 10" ed., Rio de Janeiro, Forense, 1995.

IDEM, Direito Romano, v. II, $5^{\text {a }}$ ed., Rio de Janeiro, Forense, 1995

PUGLIESE, Giovanni, Istituzioni di Diritto Romano, $2^{\text {¿ }}$ ed., Torino, Giappichelli, 1990.

VALIÑO, Emilio, Las relaciones básicas de las acciones adyecticias in $A H D E$ - Anuario de Historia del Derecho Español 38 (1968), pp. 377-480.

VIGNALI, Giovanni, Corpo del Diritto, Napoli, Vicenzo Pezzuti, 1856, Tomos II e VI. 